\title{
CORRESPONDENCE
}

\section{GONOCOCCAL FIXATION TEST}

Sir,-In his letter in the Journal of June 1944, page 81, Dr. Harkness apparently accept Dr. Price's interpretation of his (Dr. Harkness's) statement that " a positive reaction (G.C.F.T. ) is useless as a test of cure" and answers Dr. Price's challenge to produce concrete evidence by :

(1) reference to 60 cases of urethral stricture in which this test was positive in 33 per cent ;

(2) quotations of instances of misuse and misinterpretation of the test ; and

(3) expressions of opinion.

Dr. Harkness states that " the test invariably gives negative results in ano-rectal infections in the male", and then quotes a series of 110 cases which gave positive results, of which "six may very well have been false positives". Why should they have been false ?

Dr. Harkness expresses the opinion that certain organisms grown by Dr. Price, and giving positive oxidase reactions, were not gonococci. Is Dr. Harkness's practical experience of the culture and identification of the gonococcus so much greater than that of Dr. Price ?

Surely a "considered opinion"' is not concrete evidence ; will Dr. Harkness produce his evidence that "infections in the male are never limited to the anterior urethra, and that the posterior urethra is involved even during the incubation period of the disease "?

It seems a pity that Dr. Harkness should have made such a serious attack on a test which many regard as useful and on which pathologists are expending so much time and trouble ; admittedly the G.C.F.T. has its limitations, but so has the W.R., which has not been abandoned on that account.

London, S.W.1

T. E. OSMOND

Sir,-Dr. Harkness was asked to produce concrete evidence in support of his opinions concerning the complement fixation test for gonorrhoea. His reply is not impressive.

In the second paragraph of his letter in the June number of the Journal, he states that for the last seven years I have done most of his tests. According to my records these amount to some 2,000. During the same period I have done in all some 40,000 tests, 30,000 of which related to clinic patients who have been under close scrutiny both clinically and by other pathological tests. (The figures are rough but approximately correct.) He has been asked frequently to come down to Whitechapel and examine the records, but up to now has failed to do so. Furthermore, in view of his opinions I suggested the omission of the test for his patients but, oddly enough, he refused to entertain the idea.

He has lifted a phrase from its context in the third paragraph, in order to persuade himself that $\mathrm{I}$ am becoming less dogmatic concerning the interpretation of a positive reaction.

The statement that since the advent of sulphonamides the test has become even more meaningless occurs in paragraph four, but there is no indication as to how Dr. Harkness arrives at this conclusion. As far as I know, no work has been published on the effect of sulphonamide therapy in relation to the complement fixation test for gonorrhoea. I hope to remedy this omission shortly.

The persistence of gonococcal antibodies in the blood stream for years or throughout life without the existence of a gonococcal focus is postulated in paragraph five. The reason for this assertion is not apparent. At the same time it might be said that there is some experimental evidence to the contrary. Moreover, what does Dr. Harkness mean by the statement that "a positive reaction is useless as a test for cure" ?

Dr. Harkness's work as related in paragraph six seems to require little comment. However, it does appear that he has an undue faith in the value of negative results, when attempting to detect gonococci in the genito-urinary tract of patients suspected of harbouring a gonococcal focus of some years' standing. For a long time we have been trying to improve our methods, but I believe that we are still woefully inefficient.

Paragraph seven begins with this phrase: "In view of the frequency of persistently positive reactions which have no clinical significance ..." He then relates the history of a girl in the Services in order to illustrate the point. According to him the positive reaction was due to an attack of vulvo-vaginitis eighteen years previously. He does not state that it was gonococcal vulvo-vaginitis and, even if it had been, such evidence as I have been able to obtain shows that only 18 per cent of children who suffer from this disease show a positive complement fixation reaction. If this be so, then the odds against his theory being correct are at least five to one.

In 1938 I omitted to mention sulphonamide-resistant patients (paragraph six) because at that time no one was in a position to estimate the real value of these drugs ; Dr. Harkness must be well aware of this.

In paragraph nine Dr. Harkness quotes articles by two authors (Jacoby and others; Carpenter) in support of the assertion that " false positives are indeed frequent in this test" " He would get the facts into better perspective if he read the report on the Gonococcus and Gonococcal Infections (1939, p. 40) published by the United States Health Service. 
In his penultimate paragraph he says: "There are many pitfalls in diagnosing gonorrhoea on weakly positive results." It seems redundant to suggest that no experienced clinician would diagnose any disease on the strength of a pathological report.

In conclusion, might I say that I have never claimed that this test is 100 per cent efficient ; but in view of the constantly increasing number of clinicians who use it, I cannot but feel that it is establishing itself as a test of real value. On the other hand, if Dr. Harkness's letter contains all the evidence that he can adduce in support of his contentions, I am more than surprised that he has the temerity to voice his opinions with such assurance.

London, W.1

I. N. ORPWOOD PRICE

\section{NEWS AND NOTES}

\section{General Meeting of the Medical Society for the Study of Venereal Diseases}

A General Meeting of the Society was held at 11 Chandos Street, London, on . Saturday April 29 th 1944 at 2.30 p.m., with the President, Brigadier T. E. Osmond, in the chair. The Assistant Hon. Secretary (Dr. Mascall) read the minutes of the meeting held on March 25th which were confirmed and signed. On a show of hands Dr. A. F. Granger was duly elected a member of the Society. Major D. I. Williams, R.A.M.C., read a paper entitled "Sulphonamide Therapy of Gonorrhoea in the Male " (see p. 97) by Major D. I. Williams, Lt.-col. A. J. King and Major C. S. Nicol, R.A.M.C. ; thirteen members and guests took part in the discussion, to which Major Nicol replied. The President proposed a hearty vote of thanks to the authors of the paper which was accorded by applause and the meeting terminated at 4.30 p.m.

\section{Combined fever therapy and sulphadiazine in resistant gonorrhoea}

In view of the increasing number of drug-resistant cases of gonorrhoea and of the good results previously obtained by the use of fever alone, Licht and Dick have used experimentally a combination of induced hyperpyrexia with sulphadiazine administration for 119 young male patients with recently acquired sulphonamide-resistant gonorrhoea. They all had had two or more five-day courses of at least 20 grammes. After some preliminary trials a routine of treatment was established. Each patient was given 10 grammes of sulphadiazine during the 18 hours before fever therapy was begun, with the aim of obtaining a concentration in the blood of between 11 and 12 milligrams per 100 cubic centimetres at the time of induction of fever. Simultaneously fluid intake, which included sweetened orange juice, was increased to 3,000 cubic centimetres per 24 hours. Fever was induced by the use of an air-conditioned cabinet and usually occurred after 90 minutes at $120^{\circ} \mathrm{F}$. Although with fever therapy alone a temperature of $106.7^{\circ} \mathrm{F}$. is $\equiv$ necessary, sustained fever of $106^{\circ} \mathrm{F}$. for eight hours was successful in the combined treatment. The authors consider the number of cases to be too small to allow of generalization, but they record cures produced by a single period of fever lasting for 10 hours of 17 out of 18 patients, and for 8 hours of 10 out of 10 . Below 8 hours the percentage of cures dropped; in some patients fever therapy had to be stopped because of unfavourable symptoms.-Archives of Physical Therapy, April 1944.

\section{Ejaculation fluid in tests of cure in gonorrhoea}

In view of the possibilities of more rapid cure of gonorrheal infections by means of penicillin, Dub emphasizes the necessity of adequate tests of cure and reviews the various means of obtaining specimens for culture tests-urine sediments and secretions from the urethral mucosa, the prostate and the seminal vesicles. The author considers that the ejaculation fluid is more likely than any other to contain gonococci from a persistent, deep-seàted focus of infection, and recommends that the patient (after a warning against the repetition of the practice) should be induced to provide the necessary specimen by means of masturbation. A condom is worn and sterile swabs are inserted into the meatus. Both the ejaculation fluid and urine voided immediately after ejaculation are used for cultures. This method also makes it possible to study the influence of persistent gonorrhoea on the spermatozoa.-Urologic and Cutaneous Review, April 1944.

\section{Pre-employment blood tests : approval by labour representatives}

The fact that the trade union movement in the United States of America is alive to the seriousness of the present high incidence of the venereal diseases is indicated by a resolution untanimously adopted by the Bay Area Metal Trades Council of the American Federation of Labour, in favour of " voluntary pre-employment serological tests " which are conducted by managements in cooperation with the health departments. The medical officers of the firms which adopt this practice will send the specimens to the San Francisco City and County Departments of Public Health and the results will be referred to the venereal diseases division of the local department of health. All the information thus'obtained will be kept confidential, but those persons on whom tests have given positive results will, so far as is possible, be informed and persuaded to undergo treatment. On the other hand it is understood that the information shall not be used as a threat of dismissal from employment. The programme approved in this resolution is the result of cooperation between the California Social Hygiene Association, trade union officials and the venereal diseases division of the county and municipal health department.-Journal of the American Medical Association, June 1944. 